\section{$\$$ Research Square}

Preprints are preliminary reports that have not undergone peer review.

They should not be considered conclusive, used to inform clinical practice, or referenced by the media as validated information.

\title{
Clinical presentations and long-term prognosis of childhood-onset polyarteritis nodosa in a single centre: a retrospective study
}

\section{Jeong-Seon Lee}

Seoul National University Children's Hospital

JoongGon Kim

Seoul National University Children's Hospital

Soyoung Lee ( $\nabla$ leadethme@naver.com)

Seoul National University Hospital https://orcid.org/0000-0001-9627-6607

Research article

Keywords: polyarteritis nodosa, children, diagnosis, treatment, prognosis

Posted Date: August 24th, 2020

DOI: https://doi.org/10.21203/rs.3.rs-62870/v1

License: (c) (i) This work is licensed under a Creative Commons Attribution 4.0 International License. Read Full License 


\section{Abstract}

Background: Polyarteritis nodosa (PAN) is a systematic necrotizing vasculitis involving medium-sized arteries. Childhood-onset PAN ranges from mild to severe systematic disease causing damage and early mortality. As it is a rare disease in children, there is less study on clinical features, diagnosis and treatment than adults. And diagnosis occurs relatively late in most paediatric patients with polyarteritis nodosa. Therefore, this study aimed to investigate clinical manifestations, laboratory findings, treatment strategies, and long-term outcomes among patients with childhood-onset polyarteritis nodosa treated at a single-centre in Korea. We further aimed to evaluate the usefulness of the Birmingham Vasculitis Activity Score (BVAS) and Five-Factor Score (FFS) in paediatric patients.

Methods: We retrospectively analysed data collected from patients with childhood-onset PAN treated at our institution from March 2003 to February 2020.

Results: Nine patients ( 6 male and 3 female) were included in the study. The median ages at symptom onset and diagnosis were 7.6 (3-17.5) and 7.7 (3.5-17.6) years, respectively. The median follow-up duration was 7.0 (1.6-16.3) years. Eight patients were diagnosed with systemic PAN, while one was diagnosed with cutaneous PAN. All patients exhibited skin manifestations, while five exhibited Raynaud's phenomenon. Organ involvement was observed in one patient. Constitutional symptoms such as fever, arthralgia, myalgia, and weight loss were also observed. Antineutrophil cytoplasmic antibodies were absent in all patients. The median BVAS at diagnosis was 8 (range: 2-29), and one patient had an FFS of 1. Prednisolone was initially used for induction in all patients, and other drugs were added in cases refractory to prednisolone. All patients survived despite some complications such as intracranial haemorrhage or digital necrosis requiring amputation.

Conclusions: Early diagnosis and treatment may minimise sequelae in patients with childhood-onset PAN. Further multicentre studies are required to clarify the unique characteristics of childhood-onset PAN and establish treatment guidelines, early detection strategies, and biomarkers.

Trial registration: Retrospectively registered.

\section{Background}

Polyarteritis nodosa (PAN) is defined as a necrotising inflammation of medium- to small-sized arteries without glomerulonephritis or vasculitis in arterioles, capillaries, or venules, and is not associated with antineutrophil cytoplasmic antibodies (ANCAs) [1]. Although epidemiological data related to childhood-onset PAN are relatively scarce, the disease is known to be more common in adults than in children [2, 3]. Clinically, childhoodonset PAN presents as mild to severe inflammation, often leading to damage and early mortality [4]. A study from a major tertiary referral centre mainly following children with aggressive/advanced PAN reported a mortality rate of $1.1-10 \%$ [5]. Another large multicentre study from a tertiary referral centre, in which one third of patients exhibited cutaneous forms of PAN, reported a mortality rate of $1.1 \%$ [6]. Early diagnosis and appropriate treatment for childhood-onset PAN are important for minimising irreversible complications and improving prognosis [4]. Despite the presence of classification criteria, early diagnosis remains challenging because most patients with childhood-onset PAN visit the hospital due to non-specific constitutional symptoms. Myalgia and skin involvement are also significantly more frequent in patients with childhood-onset PAN than in those with adult-onset PAN [7], which may lead to further delays in diagnosis. Moreover, PAN is difficult to treat due to a lack of guidelines, and few evidencebased studies have investigated childhood-onset PAN.

There are vasculitis scoring for adult such as the Birmingham Vasculitis Activity Score (BVAS) and the Five-Factor Score (FFS). The BVAS is a clinical index of disease activity based on signs and symptoms, while the FFS is used for assessing prognosis and mortality. In previous studies, five-year mortality rates were $46 \%$ and $12 \%$ in patients with an FFS 2 and 0 , respectively [8,9]. Since vasculitis is rare in children, there is no scoring system for childhood-onset vasculitis.

The present study aimed to investigate the diagnosis, management, and outcomes of patients with childhood-onset PAN treated at a single tertiary centre in Korea over a period of approximately 17 years. We further aimed to assess the efficacy of the BVAS (version 3 ) and FFS in paediatric patients.

\section{Methods}

\section{Patients}

All patients with a diagnosis of PAN treated in our department, including those living outside our local catchment area, treated from March 2003 to February 2020 were eligible for this study. All patients were diagnosed prior to age 18 and satisfied both American College of Rheumatology criteria [2] and European League Against Rheumatism/Paediatric Rheumatology International Trials Organisation/Paediatric Rheumatology European Society (EULAR/PRINTO/PRES) criteria [10]. In accordance with these criteria, patients were diagnosed with PAN when they presented with a systemic illness characterised by either a biopsy showing necrotising vasculitis (i.e. granulocyte or mixed leukocyte infiltrates in the arterial wall) in small and medium-sized arteries or confirmed angiographic abnormalities (e.g., vascular aneurysms and occlusions). In addition, patients were required to exhibit at least one of the following five clinical items: skin signs, myalgia/muscle tenderness, peripheral neuropathy, hypertension, or renal vascular disease. Cutaneous PAN was classified as follows: necrotising vasculitis of medium-sized arteries within the skin, without

Page 2/12 
involvement of the internal organs, accompanied by fever, painful subcutaneous nodules, livedo reticularis, arthralgia, or myalgia [11, 12]. The present study was approved by the Institutional Review Board of Seoul National University Hospital in Korea (H-2004227-1119), who waived the requirement for informed consent because of the retrospective nature of the study.

\section{Data collection at diagnosis}

Each patient's medical records were reviewed in detail. From the time of diagnosis, the following data were retrieved: age; gender; the first clinical signs attributable to vasculitis; the time required to reach diagnosis (defined as the time from the first signs attributable to vasculitis until the date vasculitis was diagnosed via angiography or biopsy); signs of peripheral neuropathy; and manifestations of skin, central nervous system, genital, gastrointestinal, musculoskeletal, urologic, and renal involvement. We also collected data related to functional impairments such as fever (body temperature $>38.0^{\circ} \mathrm{C}$ ); weight loss and malaise; laboratory findings including autoantibodies, viral serology, renal parameters (proteinuria, haematuria, and serum creatinine levels), and inflammation parameters (erythrocyte sedimentation rate [ESR] and high sensitivity C-reactive protein [hs-CRP] levels). We also reviewed initial treatments, responses to treatment, and histologic/radiologic findings.

\section{Definition of disease activity and damage}

At the time of diagnosis, disease activity was assessed using version 3 of the BVAS [13]. The BVAS is a clinical index of disease activity based on signs and symptoms in nine separate organ categories (systemic, skin, mucous membranes and eyes, ear-nose-throat, chest, heart and vessels, gastrointestinal, kidney, nervous system). The maximum possible BVAS score is 63. Prognosis was assessed using the FFS [9]. FFS assessments are based on the following five items: renal insufficiency, proteinuria (> $1 \mathrm{~g} /$ day), central nervous system involvement, cardiac involvement, severe gastrointestinal involvement (e.g., bleeding, infarction, and/or pancreatitis). Each item is assigned 1 point, and higher scores are considered indicative of increased mortality.

\section{Data collection during follow-up}

During follow-up, we collected treatment-related data and recorded the timing of symptoms at relapse. We also obtained photos reflecting changes in symptoms over time and re-assessed multi-system involvement (i.e., musculoskeletal, skin, cardiovascular, renal, gastrointestinal, peripheral vascular, neuropsychiatric). Comorbidities such as diabetes mellitus and other conditions such as haemorrhagic cystitis or proteinuria were also assessed. Relapse was defined as the reoccurrence of PAN manifestations in a patient whose disease had previously been in sustained remission and required the addition of or a change in immunosuppressive agents, reinstitution of corticosteroids, and/or an increase in dose.

\section{Statistical analyses}

Categorical variables are expressed as numbers (\%), while continuous variables are expressed as medians (range: minimum-maximum) or the mean \pm standard deviation (SD). All statistical analyses were performed using IBM SPSS Statistics ver. 25.0 (IBM Co., Armonk, NY, USA).

\section{Results}

\section{Clinical characteristics at diagnosis}

Nine children (male: 6 , female: 3 ) were included in the present study. The median age at initial signs or symptoms was 7.6 years (range: $3-17.5$ years; mean: $9.1 \pm 1.54$ years), and the median age at diagnosis was 7.7 years (range: $3.5-17.6$ years; mean: $9.3 \pm 1.55$ years). The median interval from onset of initial symptoms to diagnosis was 41 days (range: $30-249$ days; mean: $90.0 \pm 30.26$ days). The median follow-up duration was 7.0 years (range: $1.6-16.3$ years; mean: $7.8 \pm 1.98$ years). All patients were vaccinated against hepatitis $B$ and had antibody levels expected to protect against the virus. No patients had a family history of rheumatic disease. Clinical manifestations and disease activity scores at diagnosis are summarised in Table 1. One patient was diagnosed with cutaneous PAN, while all others were diagnosed with systemic PAN. Skin signs were the most frequent initial manifestations of disease at diagnosis (purpura: 8, Raynaud's phenomenon: 5 , skin infarct: 3 , subcutaneous nodules: 3 , livedo reticularis: 2), followed by musculoskeletal (arthralgia: $77.8 \%$ ), systemic (fever: $66.7 \%$ ), neurologic (headache, ptosis, stroke, and gait disturbance: $11.1 \%$ ), and renal involvement (hypertension and serum creatinine elevation: $11.1 \%$ ). No patients presented with mucous membrane, eye, ear, nose, throat, pulmonary, or cardiovascular symptoms. All patients were initially diagnosed with different diseases prior to the diagnosis of childhood-onset PAN. Five were diagnosed with joint problems such as reactive arthropathy, synovitis, psoriatic arthritis, or juvenile rheumatoid arthritis, three with unspecified vasculitis, and two with erythema nodosum. Thus, most patients $(n=8)$ had taken oral or high-dose intravascular corticosteroids prior to the diagnosis of childhood-onset PAN. One received intravenous immunoglobulin G (IVIG) prior to PAN diagnosis for the treatment of truncal ataxia, left ptosis, and gait disturbance, resulting in improvement of symptoms (ptosis and truncal ataxia). 
Table 1

Clinical characteristics of nine patients at diagnosis

\begin{tabular}{|c|c|c|c|c|c|c|c|c|c|}
\hline & Patient 1 & Patient 2 & Patient 3 & Patient 4 & Patient 5 & Patient 6 & Patient 7 & Patient 8 & Patient 9 \\
\hline Sex & Male & Male & Male & Female & Male & Male & Male & Female & Female \\
\hline Subtype & Systemic & Systemic & Systemic & Systemic & Systemic & Systemic & Systemic & Cutaneous & Systemic \\
\hline $\begin{array}{l}\text { Age at } \\
\text { diagnosis, } \\
\text { years }\end{array}$ & 17.6 & 5.8 & 5.6 & 3.5 & 7.5 & 9.4 & 7.7 & 15.3 & 11.1 \\
\hline $\begin{array}{l}\text { Diagnosis } \\
\text { delay, days }\end{array}$ & 30 & 30 & 62 & 192 & 31 & 89 & 41 & 249 & 32 \\
\hline \multicolumn{10}{|c|}{ Initial symptoms at diagnosis } \\
\hline General & + & + & + & - & + & + & + & - & - \\
\hline Fever $^{\mathrm{a}}$ & + & - & - & - & - & - & - & - & - \\
\hline Weight loss ${ }^{b}$ & + & + & + & - & + & + & + & - & + \\
\hline $\begin{array}{l}\text { Arthralgia } \\
\text { Myalgia }\end{array}$ & - & - & - & - & - & - & + & - & + \\
\hline Skin & + & + & - & + & + & + & + & + & + \\
\hline Purpura & + & - & + & - & - & - & - & - & + \\
\hline $\begin{array}{l}\text { Subcutaneous } \\
\text { nodules }\end{array}$ & - & + & - & + & - & - & - & - & - \\
\hline $\begin{array}{l}\text { Livedo } \\
\text { reticularis } \\
\text { Skin infarct } \\
\text { Raynaud's } \\
\text { phenomenon }\end{array}$ & - & $\begin{array}{l}- \\
-\end{array}$ & $\begin{array}{l}- \\
-\end{array}$ & $\begin{array}{l}- \\
+\end{array}$ & $\begin{array}{l}+ \\
+\end{array}$ & $\begin{array}{l}+ \\
+\end{array}$ & $\begin{array}{l}+ \\
+\end{array}$ & $\begin{array}{l}- \\
-\end{array}$ & $\begin{array}{l}- \\
+\end{array}$ \\
\hline $\begin{array}{l}\text { Nervous } \\
\text { system } \\
\text { Ptosis }\end{array}$ & - & - & - & $\begin{array}{l}+ \\
+\end{array}$ & - & - & - & $\begin{array}{l}- \\
-\end{array}$ & - \\
\hline $\begin{array}{l}\text { Gait } \\
\text { disturbance } \\
\text { Headache } \\
\text { Stroke }\end{array}$ & - & - & - & $\begin{array}{l}+ \\
+\end{array}$ & - & - & - & - & - \\
\hline Renal & - & - & - & + & - & - & - & - & - \\
\hline $\begin{array}{l}\text { Hypertension } \\
\text { Serum } \mathrm{Cr}^{\complement}{ }^{\mathrm{C}}\end{array}$ & - & - & - & + & - & - & - & - & - \\
\hline $\begin{array}{l}\text { Abdominal } \\
\text { Abdominal } \\
\text { pain }\end{array}$ & - & - & - & + & - & - & - & - & - \\
\hline $\begin{array}{l}\text { Initial } \\
\text { diagnosis }\end{array}$ & $\begin{array}{l}\text { EN } \\
\text { Reactive } \\
\text { arthropathy }\end{array}$ & $\begin{array}{l}\text { Synovitis } \\
\text { r/o JIA }\end{array}$ & $\begin{array}{l}\text { Septic } \\
\text { arthritis } \\
\text { r/o } \\
\text { vasculitis }\end{array}$ & $\begin{array}{l}\text { Multiple } \\
\text { sclerosis }\end{array}$ & $\begin{array}{l}\text { Unspecified } \\
\text { vasculitis }\end{array}$ & $\begin{array}{l}\text { Unspecified } \\
\text { vasculitis }\end{array}$ & $\begin{array}{l}\text { Synovitis } \\
\text { r/o JIA }\end{array}$ & EN & $\begin{array}{l}\text { Psoriatic } \\
\text { arthritis }\end{array}$ \\
\hline Steroid $H x^{d}$ & + & - & + & + & + & + & + & + & + \\
\hline $\begin{array}{l}\text { Diagnostic } \\
\text { method }\end{array}$ & Skin biopsy & $\begin{array}{l}\text { Skin } \\
\text { biopsy }\end{array}$ & $\begin{array}{l}\text { Skin } \\
\text { biopsy }\end{array}$ & Angiography & Skin biopsy & Skin biopsy & $\begin{array}{l}\text { Skin } \\
\text { biopsy }\end{array}$ & $\begin{array}{l}\text { Skin } \\
\text { biopsy }\end{array}$ & $\begin{array}{l}\text { Skin } \\
\text { biopsy }\end{array}$ \\
\hline
\end{tabular}

EN: erythema nodosum; JIA: juvenile idiopathic arthritis; FFS: Five-Factor Score; BVAS: Birmingham Vasculitis Activity Score. ${ }^{\text {aD Documented }}$ axillary temperature, raised threshold to $38.0^{\circ} \mathrm{C}$; boss of dry body weight without dieting $\geq 2 \mathrm{~kg}$; ${ }^{C}$ Increase in serum creatinine $>30 \%$, from 0.4 to $0.6 \mathrm{mg} / \mathrm{dl}{ }^{\mathrm{d}}$ History, treated with prednisolone or methylprednisolone pulse therapy before prior to the diagnosis of childhood-onset PAN. 


\begin{tabular}{|c|c|c|c|c|c|c|c|c|c|}
\hline & Patient 1 & Patient 2 & Patient 3 & Patient 4 & Patient 5 & Patient 6 & Patient 7 & Patient 8 & Patient 9 \\
\hline FSS & 0 & 0 & 0 & 2 & 0 & 0 & 0 & 0 & 0 \\
\hline BVAS & 7 & 7 & 5 & 29 & 9 & 9 & 9 & 2 & 8 \\
\hline
\end{tabular}

EN: erythema nodosum; JIA: juvenile idiopathic arthritis; FFS: Five-Factor Score; BVAS: Birmingham Vasculitis Activity Score. ${ }^{a}$ Documented axillary temperature, raised threshold to $38.0^{\circ} \mathrm{C}$; boss of dry body weight without dieting $\geq 2 \mathrm{~kg}$; ${ }^{\mathrm{C}}$ Increase in serum creatinine $>30 \%$, from 0.4 to $0.6 \mathrm{mg} / \mathrm{dl}$; ${ }^{\mathrm{d}}$ History, treated with prednisolone or methylprednisolone pulse therapy before prior to the diagnosis of childhood-onset PAN.

Five (55.6\%) patients had leucocytosis (median: 14,740/uL, range: 6,960-31,290/uL), six (66.7\%) patients had thrombocytosis (median: 463,000/uL, range: $230,000-706,000 / \mathrm{uL}$ ), and three (33.3\%) patients had anaemia (median: $12.1 \mathrm{~g} / \mathrm{dL}$, range: $9.7-14.1 \mathrm{~g} / \mathrm{dL}$ ). All patients exhibited ESR elevation (median: $48 \mathrm{~mm} / \mathrm{h}$, range: $9-125 \mathrm{~mm} / \mathrm{h}$ ), while seven (77.8\%) exhibited increased hs-CRP (median: $8.13 \mathrm{mg} / \mathrm{dL}$, range: 0.01 -

$28.63 \mathrm{mg} / \mathrm{dL}$ ). No ANCAs were detected in any patient. Eight patients were diagnosed via skin biopsy. Perivascular lymphocytic infiltration was observed in seven patients (77.8\%), neutrophilic infiltration was observed in three patients (33.3\%), eosinophilic infiltration was observed in three patients, and fibrinoid necrosis (i.e., chronic PAN) was observed in one patient (11.1\%) (Fig. 1a). Patient 4 was diagnosed via angiography because no inflammatory findings were observed in the skin, including adipose tissue and vessels. In this patient, cerebral angiography and abdominal aortography revealed multiple microaneurysms in the distal cerebral, renal, and splenic arteries, which resulted in ischemic damage in the brain (Fig. 1b) and kidneys (Fig. 1c).

The median BVAS at diagnosis was 8 (mean: $9.4 \pm 2.56$; range: $2-29$ ). Only one patient (Patient 4 ) had an FFS of 2, while all others had FFS scores of zero.

\section{Treatment modality}

All patients were initially treated with prednisolone. Table 2 shows treatment modalities for all patients. In patients with mild organ involvement (i.e., peripheral neuropathy, cutaneous involvement without skin infarcts), medium- to low-dose steroids represented the treatment of choice, sometimes in combination with azathioprine. In patients with severe, life-threatening multi-system involvement (i.e., severe skin or brain infarcts, brain haemorrhage), the treatment of choice consisted of high-dose intravenous (IV) administration of 6-methylprednisolone (mPd) (10-30 mg/kg, once daily for 3 days), followed by oral prednisolone [2]. Patients who did not respond to high-dose IV mPd and those with severe skin infarcts or brain involvement were treated with high-dose IV cyclophosphamide (600 mg/m² body surface area) at 30-day intervals, oral cyclophosphamide (1$3 \mathrm{mg} / \mathrm{kg} /$ day), high-dose IV mPd again, and/or IV infliximab (Remicade®, anti-tumour necrosis factor alpha (TNF-a) inhibitor) at $5 \mathrm{mg} / \mathrm{kg}$ [14-16] depending on individual toxicity profiles or physician preference. IVIG was administered based on the patient's clinical status [17-19]. In six patients, other drugs were added for induction: cyclophosphamide in five patients (IV: 4, oral: 1), IVIG in two patients, and infliximab in one patient. Following treatment, patients were placed on maintenance therapy. Although azathioprine ( $1-2 \mathrm{mg} / \mathrm{kg})$, methotrexate (10 mg/m² body surface area), or lowdose oral prednisolone represented the drug of choice in most patients, one patient was instead treated with cyclosporine due to the side effects of oral prednisolone. Four patients (Patients 5, 6, 7, and 9) presenting with Raynaud's phenomena were treated with vasodilators such as nifedipine and IV alprostadil (Eglandin $\circledast$, prostaglandin E1). 
Table 2

Major events during follow-up for nine patients

\begin{tabular}{|c|c|c|c|c|c|c|c|c|c|}
\hline \multirow[t]{2}{*}{ Patient } & \multirow{2}{*}{$\begin{array}{l}\text { Follow- } \\
\text { up, } \\
\text { years }\end{array}$} & \multicolumn{2}{|c|}{ Initial treatment } & \multirow{2}{*}{$\begin{array}{l}1 \text { st } \\
\text { relapse, } \\
\text { days }\end{array}$} & \multirow{2}{*}{$\begin{array}{l}\text { Number } \\
\text { of } \\
\text { relapses }\end{array}$} & \multirow{2}{*}{$\begin{array}{l}\text { Symptoms } \\
\text { at relapse }\end{array}$} & \multirow[t]{2}{*}{ Operation } & \multirow{2}{*}{$\begin{array}{l}\text { Remaining } \\
\text { symptoms }\end{array}$} & \multirow{2}{*}{$\begin{array}{l}\text { Adverse drug } \\
\text { reactions }\end{array}$} \\
\hline & & Induction & Maintenance & & & & & & \\
\hline \multirow[t]{2}{*}{1} & \multirow[t]{2}{*}{2.5} & \multirow{2}{*}{$\begin{array}{l}\text { IV high } \\
\text { dose } \\
\text { mPd }\end{array}$} & AZT, & \multirow[t]{2}{*}{-} & \multirow[t]{2}{*}{0} & \multirow[t]{2}{*}{-} & \multirow[t]{2}{*}{-} & \multirow[t]{2}{*}{ Hand tremor } & \multirow[t]{2}{*}{ Cushingoid face } \\
\hline & & & PD tapering & & & & & & \\
\hline 2 & 1.6 & PO PD & PD tapering & - & 0 & - & - & - & - \\
\hline 3 & 16.3 & PO PD & PD tapering & 112 & 4 & $\begin{array}{l}\text { Fever, oral } \\
\text { ulcer, } \\
\text { arthralgia, } \\
\text { purpura, } \\
\text { Raynaud } \\
\text { phenomenon }\end{array}$ & - & $\begin{array}{l}\text { Livedo } \\
\text { reticularis }\end{array}$ & - \\
\hline \multirow[t]{3}{*}{$4^{a, b}$} & \multirow[t]{3}{*}{15.8} & \multirow{3}{*}{$\begin{array}{l}\text { PO PD } \\
\text { IV high } \\
\text { dose } \\
\text { CPM }\end{array}$} & \multirow[t]{3}{*}{ PD tapering } & \multirow[t]{3}{*}{155} & \multirow[t]{3}{*}{6} & \multirow{3}{*}{$\begin{array}{l}\text { Abdominal } \\
\text { pain } \\
\text { Headache, } \\
\text { vomiting }\end{array}$} & \multirow[t]{3}{*}{-} & \multirow{2}{*}{$\begin{array}{l}\text { Subcutaneous } \\
\text { nodule }\end{array}$} & \multirow{3}{*}{$\begin{array}{l}\text { Osteoporosis, } \\
\text { Compression } \\
\text { fracture of L1 } \\
\text { Fatty liver }\end{array}$} \\
\hline & & & & & & & & & \\
\hline & & & & & & & & & \\
\hline \multirow[t]{3}{*}{$5^{b}$} & \multirow[t]{3}{*}{12.0} & $\begin{array}{l}\text { IV high } \\
\text { dose } \\
\mathrm{mPd}\end{array}$ & PD tapering & 177 & 4 & \multirow[t]{3}{*}{$\begin{array}{l}\text { Fever, skin } \\
\text { nodule, } \\
\text { Raynaud } \\
\text { phenomenon }\end{array}$} & \multirow[t]{3}{*}{ Amputation } & \multirow[t]{3}{*}{ arthralgia } & \multirow[t]{3}{*}{$\begin{array}{l}\text { Osteochondritis, } \\
\text { hypertension }\end{array}$} \\
\hline & & PO CPM & & & & & & & \\
\hline & & IVIG & & & & & & & \\
\hline $6^{b, c}$ & 9.9 & $\begin{array}{l}\text { IV high } \\
\text { dose } \\
\text { mPd }\end{array}$ & $\begin{array}{l}\text { PD tapering, } \\
\text { Cyclosporin }\end{array}$ & 219 & 1 & $\begin{array}{l}\text { Raynaud's } \\
\text { phenomenon }\end{array}$ & Amputation & - & $\begin{array}{l}\text { Hypertension, } \\
\text { seizure, cataract, } \\
\text { gastritis }\end{array}$ \\
\hline & & $\begin{array}{l}\text { IV high } \\
\text { dose } \\
\text { CPM } \rightarrow \\
\text { PO CPM }\end{array}$ & & & & & & & $\begin{array}{l}\text { pseudomembranous } \\
\text { colitis }\end{array}$ \\
\hline $7^{b}$ & 7.0 & $\begin{array}{l}\text { IV high } \\
\text { dose } \\
\text { mPd }\end{array}$ & $\begin{array}{l}\text { AZT, MTX, } \\
\text { PD tapering }\end{array}$ & 117 & 3 & $\begin{array}{l}\text { Raynaud's } \\
\text { phenomenon, } \\
\text { Purpura }\end{array}$ & - & $\begin{array}{l}\text { Subcutaneous } \\
\text { nodule }\end{array}$ & $\begin{array}{l}\text { Hypertension, } \\
\text { Cushingoid face, } \\
\text { Buffalo hump, } \\
\text { haemorrhagic }\end{array}$ \\
\hline & & $\begin{array}{l}\text { IV high } \\
\text { dose } \\
\text { CPM } \rightarrow \\
\text { PO CPM }\end{array}$ & & & & & & & cystitis \\
\hline & & IVIG & & & & & & & \\
\hline & & $\begin{array}{l}\text { IV } \\
\text { infliximab }\end{array}$ & & & & & & & \\
\hline 8 & 3.0 & PO PD & AZT & - & 0 & - & - & - & - \\
\hline $9^{b}$ & 2.0 & $\begin{array}{l}\text { IV high } \\
\text { dose } \\
\text { mPd }\end{array}$ & $\begin{array}{l}\text { AZT, } \\
\text { PD tapering }\end{array}$ & 147 & 1 & $\begin{array}{l}\text { Raynaud's } \\
\text { phenomenon }\end{array}$ & - & Purpura & Cushingoid face \\
\hline & & $\begin{array}{l}\text { IV high } \\
\text { dose } \\
\text { CPM } \rightarrow \\
\text { PO CPM }\end{array}$ & & & & & & & \\
\hline
\end{tabular}

Major events during follow-up for nine patients. mPd, 6-methylprednisolone; AZT, azathioprine; PD, prednisolone; IVIG, intravenous immunoglobulin G; CPM, cyclophosphamide. ${ }^{a}$ Patient 4 was treated with IVIG and several mPD pulse before diagnosis as PAN; ${ }^{b}$ treated with nifedipine ointment and alprostadil for Raynaud's phenomenon; ' ${ }^{\circ}$ ral cyclosporin A was used for maintenance and stopped because of hypertensive encephalopathy.

\section{Clinical manifestations during follow-up}

The clinical manifestations observed during follow-up are presented in Table 2. During follow-up (median: 7.0 years; range: 1.6-16.3 years), six patients (66.7\%) experienced disease relapse. The median time to initial relapse was 151 days (range: $112-219$ days, mean: $154.5 \pm 16.3$ days), and the median number of relapses was 1 (range: $0-6$, mean: $2.1 \pm 0.73$ ). Relapses were mostly minor and predominantly involved the skin in all six patients. Five patients experienced multiple relapses during the follow-up period. The median time from the first maintenance treatment to relapse was 151 days (range: $46-219$ days, mean: $143.5 \pm 23.9$ days). At the time of the first induction treatment, the median duration of administration was 
53.5 days (range: $12-107$ days, mean: $62.0 \pm 13.3$ days). After relapse, the median duration of induction treatment was 17 days (range: $0-29$ days, mean: $15.8 \pm 5.1$ days). As such, the duration of hospitalisation was short during relapse. Skin necrosis was observed in the fingertips of three patients with relapse. Although two of these patients recovered completely, finger amputation was required in one patient. Patient 4 underwent surgery several times due to intracranial haemorrhage, which resulted in hemiparesis of the right side. No deaths were observed during the follow-up period (median: 7.0 years, range: $1.6-16.3$ years).

Adverse drug reactions included hypertension in three patients taking prednisolone. Among them, one experienced a seizure and exhibited proven hypertensive encephalopathy. Other adverse drug reactions due to prednisolone included Cushing syndrome, gastritis, fatty liver, osteoporosis, compression fracture, and infection. One patient experienced haemorrhagic cystitis due to cyclophosphamide treatment, which improved followed discontinuation of the drug.

\section{Disease status at the most recent follow-up}

At the most recent follow-up, two patients (Patients 5 and 6) were in clinical remission without medication, while seven patients were in clinical remission with prednisolone for maintenance therapy. In Patient 4, who has experienced multiple relapses and multi-organ involvement thus far, the last relapse occurred in December 2013. She continues to take low dose prednisolone, methotrexate, and azathioprine and engage in rehabilitation therapy.

\section{Discussion}

To our knowledge, the present study is the first to report the clinical characteristics and long-term outcomes of childhood-onset PAN in Korea and analyse the utility of the FSS and BVAS in paediatric patients. Given the partial accordance of our findings with those of previous researchers, we believe that our study provides useful data related to the clinical manifestations of childhood-onset PAN.

Previous studies $[6,12,20]$ have reported that skin involvement and arthralgia/arthritis are more common in children than in adults with PAN. In contrast, weight loss and renal, gastrointestinal, and neurologic involvement appear to be more common in adults with PAN. In the largest multicentre study to date, which included 110 paediatric patients with PAN (63 with systemic PAN) [6], 92\% of patients exhibited cutaneous lesions, while $71.4 \%, 43 \%, 33.3 \%, 14 \%$, and $11 \%$ exhibited myalgia, hypertension, central nervous system involvement, cardiac involvement, and pulmonary involvement, respectively. In another large paediatric series including 69 patients with systemic PAN [21], presenting features by organ system were as follows: skin involvement in $88 \%$, myalgia in $83 \%$, arthralgia/arthritis in $75 \%$, weight loss in $64 \%$, fever in $60 \%$, renal involvement in $19 \%$, severe gastrointestinal involvement in $10 \%$, and central nervous system involvement in $10 \%$. In accordance with previous findings, skin and joint symptoms were noted in most of our patients, although rates of myalgia were lower in our study. These findings suggest that cutaneous manifestations with nonspecific systemic symptoms in children necessitate referral to a specialist in paediatric rheumatology or dermatology to ensure prompt clinical diagnosis.

Laboratory features including serum creatinine, urinalysis, liver function tests, and muscle enzyme concentrations were largely non-specific and included elevated ESR and hs-CRP in most cases. However, these findings are neither sensitive nor specific for the diagnosis of PAN. That is, there are no laboratory findings that can be used to definitely diagnose either childhood- or adult-onset PAN. Evidence suggests that childhood-onset PAN affects girls more than boys, in contrast to adult-onset PAN $[8,20,21]$. Although we enrolled only a small number of patients, the prevalence of PAN appeared slightly higher in boys $(n=6)$ than in girls $(n=3)$. While previous studies have reported mortality rates ranging from $1-4 \%$ [6, 21], no deaths were observed during our study period.

We also evaluated BVAS and FFS in our patients. No patients exhibited involvement of the mucous membranes, eyes, ears, nose, throat, chest, or cardiovascular system (used for BVAS assessment). Skin manifestations, especially Raynaud's phenomenon with or without digital necrosis, were observed in six and five patients at diagnosis and at the first relapse, respectively. For the BVAS, Raynaud's phenomena are not considered, and the contribution of skin symptoms is relatively small. However, Raynaud's phenomena and skin symptoms greatly influenced the treatment strategies adopted for our patients. These findings suggest that more detailed subdivisions of skin manifestations are required to develop a new vasculitis scoring system for children. The highest FFS (2 points) was observed in Patient 2, who experienced hemiplegia due to cerebral bleeding and haematoma as well as several relapses. Fortunately, disease activity in Patient 2 has been well controlled with low-dose prednisolone, azathioprine, and methotrexate. Although this finding indicates that the FFS may be useful for predicting mortality in both childhood-and adult-onset PAN, our study was limited by the small number of included patients. As few patients exhibited multi-organ involvement, it was difficult to assess the utility of the FFS in paediatric patients.

The most appropriate treatments for PAN remain to be determined. Given the rarity of the disease, no treatment guidelines have been established, especially for children. In our study, four patients initially presented with Raynaud's phenomena in the fingers. Finger amputation was necessary in two of these patients due to delayed diagnosis (Fig. 2a). In contrast, two patients who had been diagnosed earlier recovered without the need for amputation (Fig. 2b). These findings suggest that early diagnosis and aggressive intervention can help to improve long-term outcomes. Initial treatment with corticosteroids is important achieving remission in patients with adult-onset PAN, and steroid monotherapy is currently recommended for patients with mild PAN $[22,23]$. In addition, cyclophosphamide is considered to induce remission, and immunosuppressive agents such as azathioprine or methotrexate are recommended to maintain remission or as steroid-sparing agents [24]. For induction, all patients in the present 
study were treated with high-dose corticosteroids or corticosteroid pulse therapy. The degree of multi-organ involvement and the response to initial treatment are the principal determinants for the addition of cyclophosphamide, IVIG, or infliximab. Given the lack of controlled studies, IVIG treatment for vasculitis has been restricted to patients exhibiting resistance to corticosteroids and immunosuppressive therapy [25]. Both steroids and cyclophosphamide are associated with several side effects when used in children, including growth problems, metabolic syndrome, adverse psychological effects, hypertension, infection, malignancy, and infertility [26-28]. In the present study, we also observed adverse drug reactions including Cushingoid face $(n=3)$, hypertension $(n=3)$, infection $(n=2)$, osteoporosis $(n=1)$, and haemorrhagic cystitis ( $n=1)$. These complications are particularly worrisome for children with many years of life ahead of them. Although we did not detect late complications such as malignancy or infertility in our study, physicians should screen for signs of infertility and malignancy in patients exposed to cyclophosphamide.

Recent reports have highlighted the safety and efficacy of the anti-TNF-a inhibitor infliximab in patients with PAN [29, 30]. Indeed, treatment of skin necrosis with infliximab appeared effective in our study. Although not used in the current study, the interleukin- 6 blocker tocilizumab has also shown promise for the treatment of vasculitis [31,32]. Strategies that aim to reduce the treatment burden as much as possible should be a major goal for physicians when attempting to achieve remission. Furthermore, paediatricians should closely monitor growth, psychological status, and long-term outcomes in patients with childhood-onset PAN.

Multiple cases of systemic and cutaneous PAN have been identified in some Georgian Jewish or German families, consistent with an autosomal recessive inheritance-induced mutation in the adenosine deaminase 2 ( $A D A 2$ )-encoding gene $C E C R 1$ (cat-eye syndrome chromosome region candidate 1) [4]. The discovery of this association between $A D A 2$ and vasculitis has led to reconsideration in most cases of childhood-onset PAN. Hence, it remains critical to evaluate family history and identify ADA2 mutations when considering a diagnosis of PAN, as anti-TNF-a agents and $A D A 2$ replacement therapy may be warranted in some cases [30].

This study has several strengths. First, all patients were managed by two expert physicians affiliated with Seoul National University Children's Hospital, helping to ensure homogenous referral and treatment patterns among patients. In addition, patients were followed up for a relatively long period of time, allowing us to better characterise disease status based on clinical and laboratory information. Despite these strengths, the study possesses some limitations of note, including its single-centre retrospective design, which prevented us from assessing correlations between various treatment strategies and final outcomes. Furthermore, we were unable to perform a comprehensive multivariate analysis including clinical manifestations, FFS, and BVAS due to the small number of included patients. Lastly, we cannot exclude the potential for bias due to the inclusion of patients with more severe disease, who may be more likely to consult at tertiary referral centres.

\section{Conclusion}

Childhood-onset PAN is a rare disease that can be associated with severe complications despite appropriate treatment. Patients exhibiting central nervous system involvement, either at onset or during the disease course due to treatment, tend to experience the worst outcomes. Therefore, early diagnosis and aggressive treatment for childhood-onset PAN are important for improving prognosis without sequelae. Although our study provides some insight, further multicentre studies are required to clarify the unique characteristics of childhood-onset PAN and establish treatment guidelines, early detection strategies, and biomarkers.

\section{List Of Abbreviations}

PAN: polyarteritis nodosa

ANCAs: antineutrophil cytoplasmic antibodies

BVAS: Birmingham Vasculitis Activity Score

FSS: Five-Factor Score

EULAR/PRINTO/PRES: European League Against Rheumatism/Paediatric Rheumatology International Trials Organisation/Paediatric Rheumatology European Society

ESR: erythrocyte sedimentation rate

hs-CRP: high sensitivity C-reactive protein

SD: standard deviation

IVIG: intravenous immunoglobulin G

IV: intravenous

ADA2: adenosine deaminase 2 


\section{Declarations}

Ethics approval and consent to participate

This study was conducted in accordance with the Declaration of Helsinki. The Institutional Review Board of Seoul National University Hospital in Korea approved the research protocol ( $\mathrm{H}-2004227-1119)$.

\section{Consent for publication}

The Institutional Review Board of Seoul National University Hospital in Korea, approving this study waived the requirement for informed consent because of the retrospective nature of the study

Availability of data and materials.

The datasets used and/or analysed during the current study are available from the corresponding author on reasonable request.

\section{Competing interests}

The authors declare that they have no competing interests.

Funding

No specific finding was received from any bodies in the public, commercial, or not-for-profit sectors to carry out the work described in this article.

\section{Authors' contributions}

This study was designed, directed, and coordinated by Soyoung Lee. Jeong-Seon Lee assembled and analysed clinical data and wrote the manuscript. Joong-Gon Kim contributed to the revision of the manuscript. All authors have read and approved the final version of the manuscript.

\section{Acknowledgements}

We thank the patients, their parents, and all physicians who have cared for them. This retrospective study was performed within the Department of Paediatrics at Seoul National University Children's Hospital in Korea.

\section{References}

1. Jennette JC, Falk RJ, Bacon PA, Basu N, Cid MC, Ferrario F, et al. 2012 revised International Chapel Hill Consensus Conference Nomenclature of Vasculitides. Arthritis Rheum 2013;65(1):1-11.

2. Hernandez-Rodriguez J, Alba MA, Prieto-Gonzalez S, Cid MC. Diagnosis and classification of polyarteritis nodosa. J Autoimmun 2014;48-49:849.

3. Gardner-Medwin JMM, Dolezalova P, Cummins C, Southwood TR. Incidence of Henoch-Schonlein purpura, Kawasaki disease, and rare vasculitides in children of different ethnic origins. Lancet 2002;360(9341):1197-202.

4. Navon Elkan P, Pierce SB, Segel R, Walsh T, Barash J, Padeh S, et al. Mutant adenosine deaminase 2 in a polyarteritis nodosa vasculopathy. $N$ Engl J Med 2014;370(10):921-31.

5. Dillon MJ, Eleftheriou D, Brogan PA. Medium-size-vessel vasculitis. Pediatr Nephrol 2010;25(9):1641-52.

6. Ozen S, Anton J, Arisoy N, Bakkaloglu A, Besbas N, Brogan P, et al. Juvenile polyarteritis: results of a multicenter survey of 110 children. J Pediatr 2004;145(4):517-22.

7. Sönmez H, Armagan B, Ayan G, Barut K, Batu ED, Erden A, et al. FRI0496 Polyarteritis nodosa: over 20 years' clinical experience. Ann Rheum Dis 2018;77:775-6.

8. Guillevin L, Lhote F, Gayraud M, Cohen P, Jarrousse B, Lortholary O, et al. Prognostic factors in polyarteritis nodosa and Churg-Strauss syndrome. A prospective study in 342 patients. Medicine 1996;75(1):17-28.

9. Guillevin L, Pagnoux C, Seror R, Mahr A, Mouthon L, Le Toumelin P, et al. The Five-Factor Score revisited: assessment of prognoses of systemic necrotizing vasculitides based on the French Vasculitis Study Group (FVSG) cohort. Medicine 2011;90(1):19-27.

10. Yates M, Watts RA, Bajema IM, Cid MC, Crestani B, Hauser T, et al. EULAR/ERA-EDTA recommendations for the management of ANCAassociated vasculitis. Ann Rheum Dis 2016;75(9):1583-94.

11. Nakamura T, Kanazawa N, Ikeda T, Yamamoto Y, Nakabayashi K, Ozaki S, et al. Cutaneous polyarteritis nodosa: revisiting its definition and diagnostic criteria. Arch Dermatol Res 2009;301(1):117-21.

12. Pagnoux C, Seror R, Henegar C, Mahr A, Cohen P, Le Guern V, et al. Clinical features and outcomes in 348 patients with polyarteritis nodosa: a systematic retrospective study of patients diagnosed between 1963 and 2005 and entered into the French Vasculitis Study Group Database. 
Arthritis Rheum 2010;62(2):616-26.

13. Mukhtyar C, Lee R, Brown D, Carruthers D, Dasgupta B, Dubey S, et al. Modification and validation of the Birmingham Vasculitis Activity Score (version 3). Ann Rheum Dis 2009;68(12):1827-32.

14. Al-Bishri J, le Riche N, Pope JE. Refractory polyarteritis nodosa successfully treated with infliximab. J Rheumato/ 2005;32(7):1371-3.

15. Atzeni F, Doria A, Carrabba M, Turiel M, Sarzi-Puttini P. Potential target of infliximab in autoimmune and inflammatory diseases. Autoimmun Rev 2007;6(8):529-36.

16. Keystone EC. The utility of tumour necrosis factor blockade in orphan diseases. Ann Rheum Dis 2004;63 Suppl 2:ii79-ii83.

17. Gonzalez-Fernandez MA, Garcia-Consuegra J. Polyarteritis nodosa resistant to conventional treatment in a pediatric patient. Ann Pharmacother 2007;41(5):885-90.

18. Kroiss M, Hohenleutner U, Gruss C, Glaessl A, Landthaler M, Stolz W. Transient and partial effect of high-dose intravenous immunoglobulin in polyarteritis nodosa. Dermatology 2001;203(2):188-9.

19. Steinbrecher A, Berlit P. Intravenous immunoglobulin treatment in vasculitis and connective tissue disorders. J Neuro/ $2006 ; 253$ Suppl 5:V39-49.

20. Erden A, Batu ED, Sonmez HE, Sari A, Armagan B, Arici ZS, et al. Comparing polyarteritis nodosa in children and adults: a single center study. Int $J$ Rheum Dis 2017;20(8):1016-22.

21. Eleftheriou D, Dillon MJ, Tullus K, Marks SD, Pilkington CA, Roebuck DJ, et al. Systemic polyarteritis nodosa in the young: a single-center experience over thirty-two years. Arthritis Rheum 2013;65(9):2476-85.

22. Guillevin L, Cohen P, Mahr A, Arene JP, Mouthon L, Puechal X, et al. Treatment of polyarteritis nodosa and microscopic polyangiitis with poor prognosis factors: a prospective trial comparing glucocorticoids and six or twelve cyclophosphamide pulses in sixty-five patients. Arthritis Rheum 2003;49(1):93-100.

23. Ribi C, Cohen P, Pagnoux C, Mahr A, Arene JP, Puechal X, et al. Treatment of polyarteritis nodosa and microscopic polyangiitis without poorprognosis factors: A prospective randomized study of one hundred twenty-four patients. Arthritis Rheum 2010;62(4):1186-97.

24. Guillevin L, Lhote F, Amouroux J, Gherardi R, Callard P, Casassus P. Antineutrophil cytoplasmic antibodies, abnormal angiograms and pathological findings in polyarteritis nodosa and Churg-Strauss syndrome: indications for the classification of vasculitides of the polyarteritis Nodosa Group. Br J Rheumatol 1996;35(10):958-64.

25. Weiss PF. Pediatric vasculitis. Pediatr Clin North Am 2012;59(2):407-23.

26. Mushtaq T, Ahmed SF. The impact of corticosteroids on growth and bone health. Arch Dis Child 2002;87(2):93-6.

27. Coddington DA, Cheng TL. Corticosteroids. Pediatr Rev 2002;23(4):146-7.

28. Teles KA, Medeiros-Souza P, Lima FAC, Araujo BG, Lima RAC. Cyclophosphamide administration routine in autoimmune rheumatic diseases: a review. Rev Bras Reumatol Engl Ed 2017;57(6):596-604.

29. Matsuo S, Hayashi K, Morimoto E, Kato A, Sada KE, Watanabe H, et al. The successful treatment of refractory polyarteritis nodosa using infliximab. Intern Med 2017;56(11):1435-8.

30. Ginsberg S, Rosner I, Slobodin G, Rozenbaum M, Kaly L, Jiries N, et al. Infliximab for the treatment of refractory polyarteritis nodosa. Clin Rheumatol 2019;38(10):2825-33.

31. Silva-Fernandez L, Loza E, Martinez-Taboada VM, Blanco R, Rua-Figueroa I, Pego-Reigosa JM, et al. Biological therapy for systemic vasculitis: a systematic review. Semin Arthritis Rheum 2014;43(4):542-57.

32. Saunier A, Issa N, Vandenhende MA, Morlat P, Doutre MS, Bonnet F. Treatment of polyarteritis nodosa with tocilizumab: a new therapeutic approach? RMD Open 2017;3(1):e000446.

\section{Figures}


A

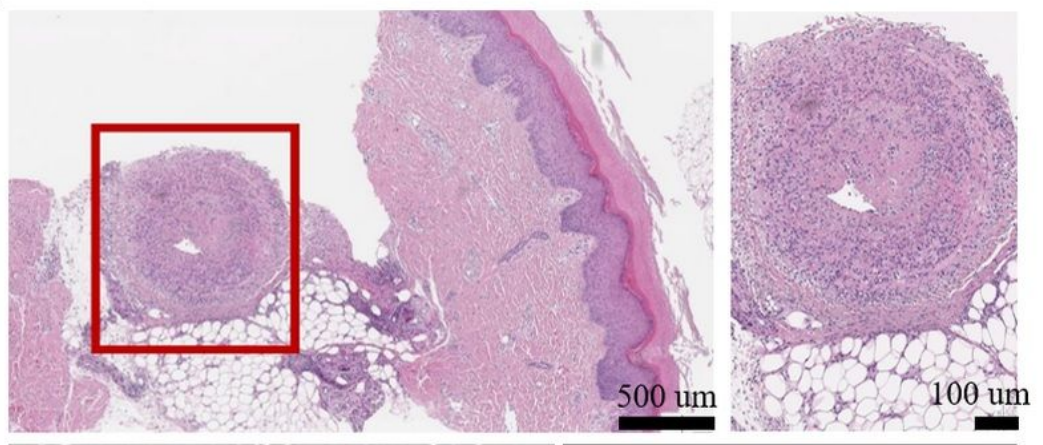

$\mathrm{B}$

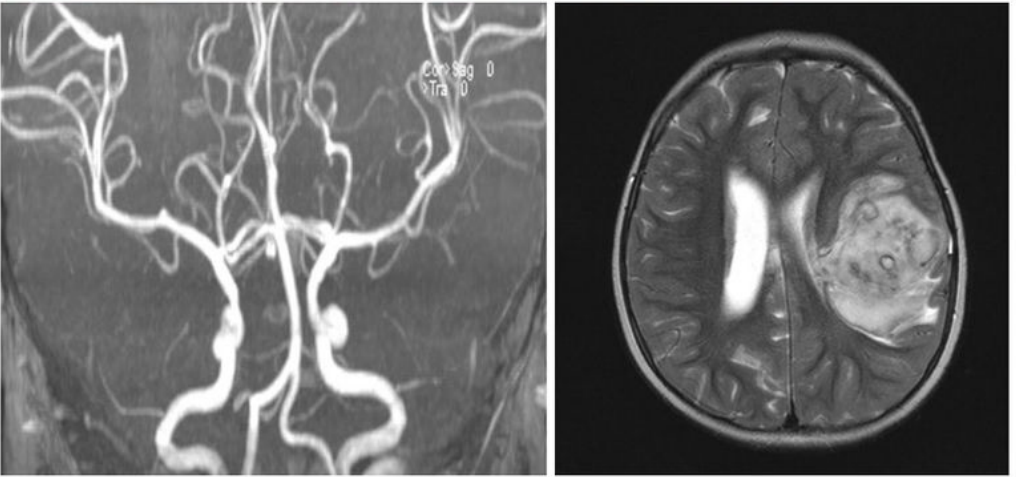

$\mathrm{C}$

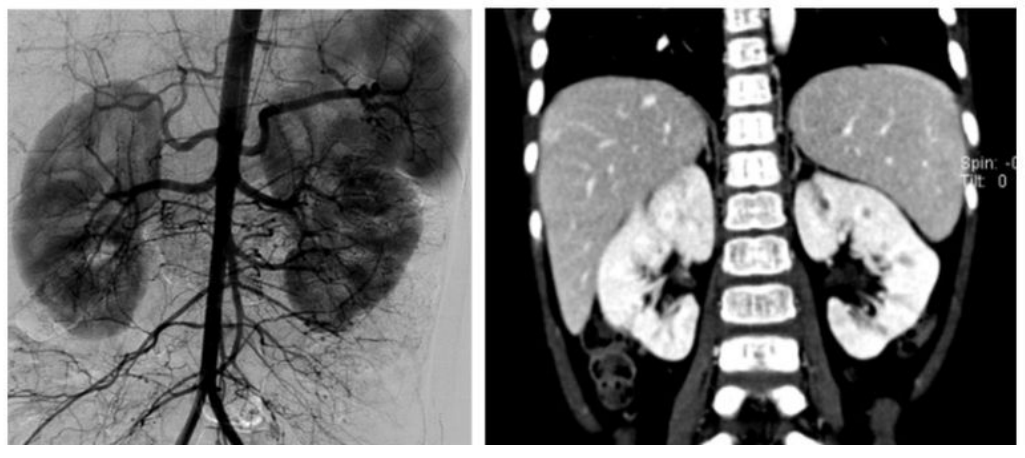

Figure 1

Pathologic and radiologic findings. a Histological findings for skin tissue: Medium-sized vessels in the subcutis exhibiting lympho-histiocytic, some neutrophilic, and slight eosinophilic infiltration. b Brain arteriography showing small micro-aneurysms in the distal cerebral arteries and brain MRI showing brain infarction. c Ascending aortography showing multiple aneurysms and peripheral vascular luminal narrowing in the superior mesenteric artery, inferior mesenteric artery, and renal (bilateral), splenic, and right coronary arteries. Abdominal CT showing renal infarction and renal cortical thickening. MRI: magnetic resonance imaging; CT: computed tomography. 
A
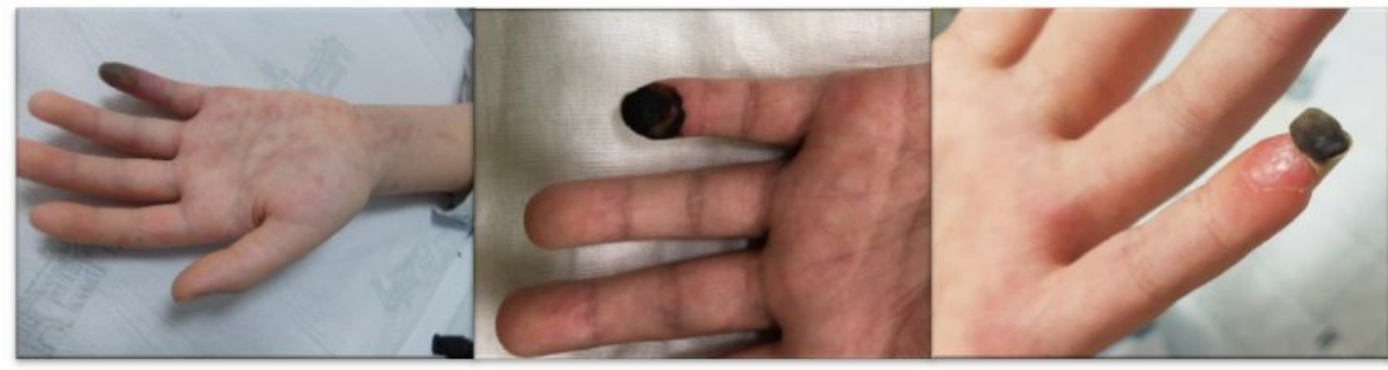

2 weeks

2 months

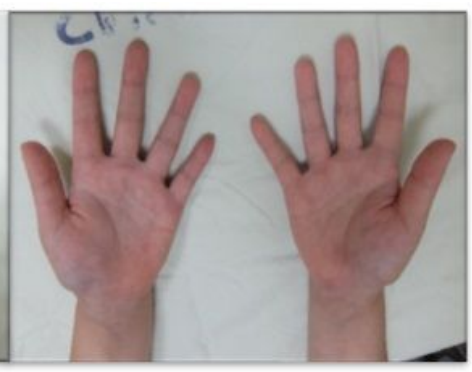

At diagnosis

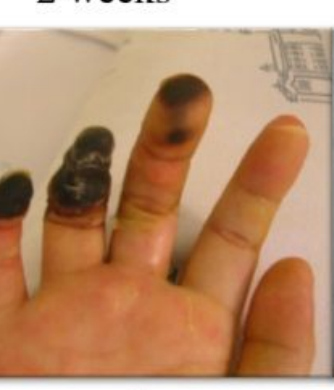

2 weeks

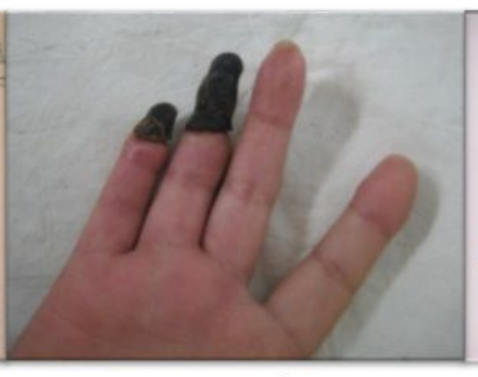

5 months

\section{5 months}

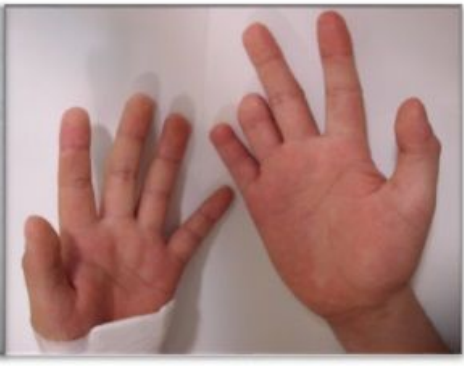

15 months

Figure 2

Treatment responses and final outcomes for patients with skin involvement. a This patient exhibited Raynaud's phenomenon in the 3rd, 4th, and 5th fingertips as well as skin necrosis in the 5th fingertip at diagnosis. Early diagnosis and aggressive treatment allowed for preservation of the 5 th finger despite slight shortening. b This patient experienced finger pain at the initial visit and gangrene in the 3rd, 4th, and 5th fingers, which worsened at the time of transfer despite corticosteroid treatment. Despite aggressive treatment, amputation of the 4th and 5th fingertips was necessary. 